\title{
A155 DIFFERENTIAL DISTRIBUTION OF A PEGYLATED FAB' INTO INFLAMED VERSUS NORMAL TISSUE COMPARED WITH AN IGG IN ARTHRITIS AND COLITIS MODELS
}

M Marenzana, A Eddleston, A Vugler, A Nesbitt Inflammation Discovery, UCB, Slough, UK

\subsection{6/ard.2010.129650f}

Purpose Certolizumab pegol (CZP), a PEGylated Fab', has been shown to distribute to inflamed versus normal tissue at a ratio of 3.8 in a collagen-induced arthritis (CIA) mouse model, whereas adalimumab (ADA), an IgG, had a ratio of $1.9 .{ }^{1}$ The objective of this study was to compare PEGylated Fab' and IgG distribution by determining the consequence of tumour necrosis factor (TNF) binding on the distribution of these reagents in inflamed versus normal tissue in the CIA and DSS gut colitis models.

Methods An anti-mouse TNF antibody with an affinity for mouse TNF, similar to the anti-human reagents CZP and ADA, was used for this study. Both the PEGylated Fab' and IgG2a versions of this antibody were labelled with one of two fluorescent dyes: Alexa 680 (CIA model) and Alexa 790 (DSS model). The reagents were given intravenously at $2 \mathrm{mg} / \mathrm{kg}$ in the CIA model and subcutaneously at $10 \mathrm{mg} / \mathrm{kg}$ in the DSS model. In both models, control animals were similarly dosed. In the CIA model, paws were imaged in vivo at various time points up to $26 \mathrm{~h}$ post-administration using an IVIS imager. In the DSS model, the colons were removed after $24 \mathrm{~h}$ and imaged using the IVIS imager ex vivo by drawing a region of interest around the whole excised colon.

Results Both the IgG and PEGylated Fab' penetrated inflamed tissue more effectively than the non-inflamed tissue in both the CIA and DSS models. However, in both models the ratio of distribution in inflamed versus normal tissue was higher for the PEGylated Fab' than the IgG. In the CIA model, the ratio was 2.3 for the PEGylated Fab' vs 1.7 for the IgG after $1 \mathrm{~h}(\mathrm{p}=01$ by unpaired two-tailed t test); the ratio remained significant at all time points tested out to $26 \mathrm{~h}$. In the DSS model, the ratio was 3.1 vs 2.1, respectively, after $26 \mathrm{~h}(\mathrm{p}=0.02)$.

Conclusions PEGylated Fab' had a higher inflamed to normal tissue ratio than the IgG in two different mouse models of inflammation. This confirms previous observations concerning the effect of PEG on the distribution of proteins and suggests that antigen binding does not greatly affect distribution. 
Effective targeting of inflamed tissue is desired for an anti-inflammatory agent and may be an important consideration for effective treatment of inflammatory disorders.

\section{REFERENCE}

1. Nesbitt A, et al. Ann Rheum Dis 2007;66(Suppl II):296. 